Article

\title{
Laser Treatment as a New Approach to the Passivation of Iron-Based Historical Monuments
}

\author{
Iuliia Ruzankina ${ }^{1,2, *}$, Vadim Parfenov ${ }^{3}$ (D) Oleg Vasiliev ${ }^{4}$, Oleg Zotov ${ }^{5}$ and Alexandra Zotova ${ }^{5}$ \\ 1 Department of Mathematics and Physics, Univesita Cattolica del Sacro Cuore, I-25121 Brescia, Italy \\ 2 Department of Chemistry, KU Leuven, Celestijnenlaan 200D, 3001 Leuven, Belgium \\ 3 Department of Photonics, St. Petersburg Electrotechnical University, 197376 Saint Petersburg, Russia; \\ vaparfenov@etu.ru \\ 4 LLC 'Laser Center', 195176 Saint Petersburg, Russia; tesla_90@mail.ru \\ 5 Laboratory of Synthesis New Materials and Structures, Peter the Great St. Petersburg Polytechnic University, \\ 195251 Saint Petersburg, Russia; zog-58@mail.ru (O.Z.); zotova_ao@spbstu.ru (A.Z.) \\ * Correspondence: ruzankinajulia@gmail.com
}

Citation: Ruzankina, I.; Parfenov, V.; Vasiliev, O.; Zotov, O.; Zotova, A. Laser Treatment as a New Approach to the Passivation of Iron-Based Historical Monuments. Quantum Beam Sci. 2022, 6, 9. https:// doi.org/10.3390/qubs6010009 Academic Editors: Swee Leong Sing and Wai Yee Yeong

Received: 20 January 2022

Accepted: 14 February 2022

Published: 16 February 2022

Publisher's Note: MDPI stays neutral with regard to jurisdictional claims in published maps and institutional affiliations.

Copyright: (C) 2022 by the authors. Licensee MDPI, Basel, Switzerland. This article is an open access article distributed under the terms and conditions of the Creative Commons Attribution (CC BY) license (https:// creativecommons.org/licenses/by/ $4.0 /)$.

\begin{abstract}
This article is devoted to the study of the possibility of the passivation of iron-based metallic materials. The experimental results obtained for the laser treatment of carbon steel model samples by the radiation of repetitively pulsed and continuous-wave $1.064 \mu \mathrm{m} \mathrm{Nd:YAG} \mathrm{lasers} \mathrm{are} \mathrm{described.}$ It is shown that the laser treatment allows the formation of dense protection films, 62-77 microns thick, on the steel surface. The films enhance the anticorrosion properties of the metal. Exposure to laser radiation reduces the surface roughness (from $R_{a}=0.53 \mu \mathrm{m}$ to $R_{a}=0.38 \mu \mathrm{m}$ ). Laser radiation power densities of $10.2 \times 10^{5} \mathrm{~W} / \mathrm{cm}^{2}$ and $10.7 \times 10^{5} \mathrm{~W} / \mathrm{cm}^{2}$ for these two laser generating modes, respectively, correspond to the optimum (in terms of the degree of corrosion resistance) modes of steel treatment. The conducted studies show that the application of Nd: YAG lasers is a promising method for the surface passivation of artworks created from steel and cast iron. One of the most promising applications of the proposed method for the anticorrosion protection of iron is the passivation of the surface of iron-based historical monuments.
\end{abstract}

Keywords: laser passivation; Nd:YAG laser; anticorrosion coating; steel; cultural heritage; historical monument; artworks; restoration

\section{Introduction}

One of the most important practical tasks in modern museum work is the passivation of the surface of cultural heritage $(\mathrm{CH})$ objects made of iron, steel, and cast iron. In the conservation of such objects, restorers frequently have to deal with the removal of corrosion products. This is a very difficult task in itself, since the corrosion layer thickness of many monuments (primarily archaeological objects) can be significant (up to $1 \mathrm{~cm}$ ). However, this problem is aggravated by the fact that the reoccurring formation of the foci of corrosion on the surface of such objects is possible after the completion of the restoration process. This puts the task of developing effective technologies for creating inhibitory (protective) coatings on the surface of monuments on the agenda.

Corrosion inhibitors are the substances that, when in a corrosive environment in sufficient concentrations, dramatically slow down or even stop the corrosive degradation of metal. There are several different types of inhibitors; however, in terms of restorationrelated tasks, the most relevant is the application of coatings which enhance the resistance of museum objects to the effects of atmospheric corrosion. Most often, wax and various types of lacquers are used as inhibitors in the conservation of $\mathrm{CH}$ objects; but in recent years special protective materials have emerged, including those made of inorganic materials [1].

According to the mechanism of action, inhibitors can be divided into two types: passivating and adsorption. Adsorption-based corrosion inhibitors are adsorbed on the surface 
of a protected artifact, forming a film, and inhibit electrochemical reactions (sometimes forming a thin monomolecular film is sufficient for this). Adsorption inhibitors are most often surface-active agents, as well as organic compounds which, owing to their impact on the artifact, additionally enhance the protective properties of the oxide film. The presence of oxygen in a corrosive environment contributes to enhancing the protective effect of adsorption corrosion inhibitors. If the oxide film is unstable, then the adsorption of the inhibitor on the metal surface will be hampered, with the oxygen having no additional impact.

Passivating corrosion inhibitors play an important role in the formation of a protective film on the metal surface. Most often, passivators are inorganic compounds with oxidising properties (nitrites, molybdates, and chromates). Passivating compounds are considered more effective than most non-passivating ones. Thus, the passivation of metals involves the transition of the metal surface into an inactive, passive state, which is associated with the formation of thin surface layers of chemical compounds that prevent corrosion.

In modern technology, passivation refers to methods used to protect metals from corrosion through chemical treatments or technological processes leading to the creation of an oxide film on the treated surface. One of the most advanced approaches for the creation of passivating coatings in industry is the laser treatment of metal surfaces. In particular, from the scientific literature, the possibility of protecting metals from corrosion as a result of the creation of patterned micro- and nanostructures on their surface under the influence of radiation from solid-state lasers with pico- and femtosecond pulse duration has been reported [2,3]. Such a pulse duration can be achieved in the so-called mode-locking generation regime of lasers. However, the laser passivation of metals is still not applied in the restoration of $\mathrm{CH}$ objects. One of the possible reasons for this is the fact that pico- and femtosecond laser systems are very expensive, and only highly qualified professionals are able to work with them.

In order to further develop methods for the laser restoration of metals in museums, a study was conducted on the possibility of creating anticorrosive coatings on the surface of iron objects using laser treatment. In this case, unlike in the above-mentioned works, the authors of this article proposed and experimentally proved the possibility of using continuous-wave and repetitively pulsed Nd:YAG lasers for this purpose [2,3]. Lasers operating in such generation regimes are much cheaper than mode-locked laser systems and can be easily exploited even by professional restorers who do not have an engineering background.

It should be noted that research on the possibility of the passivation of metal monuments using pulsed Nd:YAG lasers is also currently being carried out by the scientific group of S. Siano et al. [4,5]. In the works by S. Siano, experiments were carried out focusing on the treatment of iron surfaces using a Nd:YAG laser that generated pulses at a fundamental wavelength of $1.064 \mu \mathrm{m}$ and operated in three different generating modes: Q-switched mode, long Q-switched mode (LQS-Q-switched mode with increased pulse duration), and Short Free Running mode (SFR-free-running mode with shortened pulse duration). The treatment of the metal was performed using single laser pulses.

Even S. Siano et al. $[4,5]$ themselves consider their results as preliminary, since they explored the task of iron passivation only in relation to model samples and certain types of historical monuments with the foci of corrosion on their surfaces. As a result of the treatment of corroded areas by radiation from a laser operating in SFR mode (with a pulse duration of $20 \mu \mathrm{s}$ ) and heating, the phase transformation of iron oxides occurred-iron oxide $(\mathrm{FeO})$ was converted to magnetite $\left(\mathrm{Fe}_{3} \mathrm{O}_{4}\right)$. Although magnetite is a stable iron compound that is affected by corrosion, such an approach to the problem of the passivation of monuments seems to be rather controversial [6]. Firstly, it does not solve the problem of the anticorrosive protection of "clean" (i.e., without foci of corrosion) surfaces. Secondly, the formation of magnetite leads to the appearance of a grey-black colour on the laser-treated surface areas, which may be unacceptable in terms of the aesthetic properties of $\mathrm{CH}$ objects.

The approach suggested by the authors of this article is more universal, since it allows the formation of protective anticorrosion layers on "clean" surfaces of monuments made of 
iron and steel. In addition, in terms of the effect achieved, CW and nanosecond Nd:YAG lasers are alternatives to the above-mentioned pico- and femtosecond laser systems but are simpler to operate and maintain; this is very important from the perspective of routine museum work. It should also be noted that the results obtained in this work are a further development of research on the laser anticorrosion treatment of metals in general, which the authors have devoted themselves to during the last few years [7-11]. This means that the proposed approach is also very useful for iron treatment in industry.

\section{Materials and Methods}

In order to test the technology involved in the laser passivation of historical monuments made of iron, small carbon steel plates were selected as the model samples (with areas up to $5 \mathrm{~cm}^{2}$ and thicknesses of 3-5 mm). With electron microscopy, the following chemical composition data were obtained: iron $(\mathrm{Fe})-83.4 \%$; carbon $(\mathrm{C})-13.5 \%$; silicon (Si) $-0.7 \%$; manganese $(\mathrm{Mn})-0.5 \%$. In addition to these elements, alloying elements such as nickel $(\mathrm{Ni})$, chromium $(\mathrm{Cr})$, copper $(\mathrm{Cu})$, and cobalt $(\mathrm{Co})$ were also present in the samples in low concentrations. In Russia, a steel grade with such a chemical composition is called Steel20. This steel was chosen for use in experimental studies due to the fact that many historical monuments were created of ferrous metals, which are close to Steel20 in terms of their chemical composition.

Our samples were treated using a Nd:YAG laser at a wavelength of $\lambda=1064 \mu \mathrm{m}$ in repetitively pulsed and continuously pulsed modes (Figure 1). A laboratory model developed in the research institute "Polyus" (Moscow) was used in the experiments.

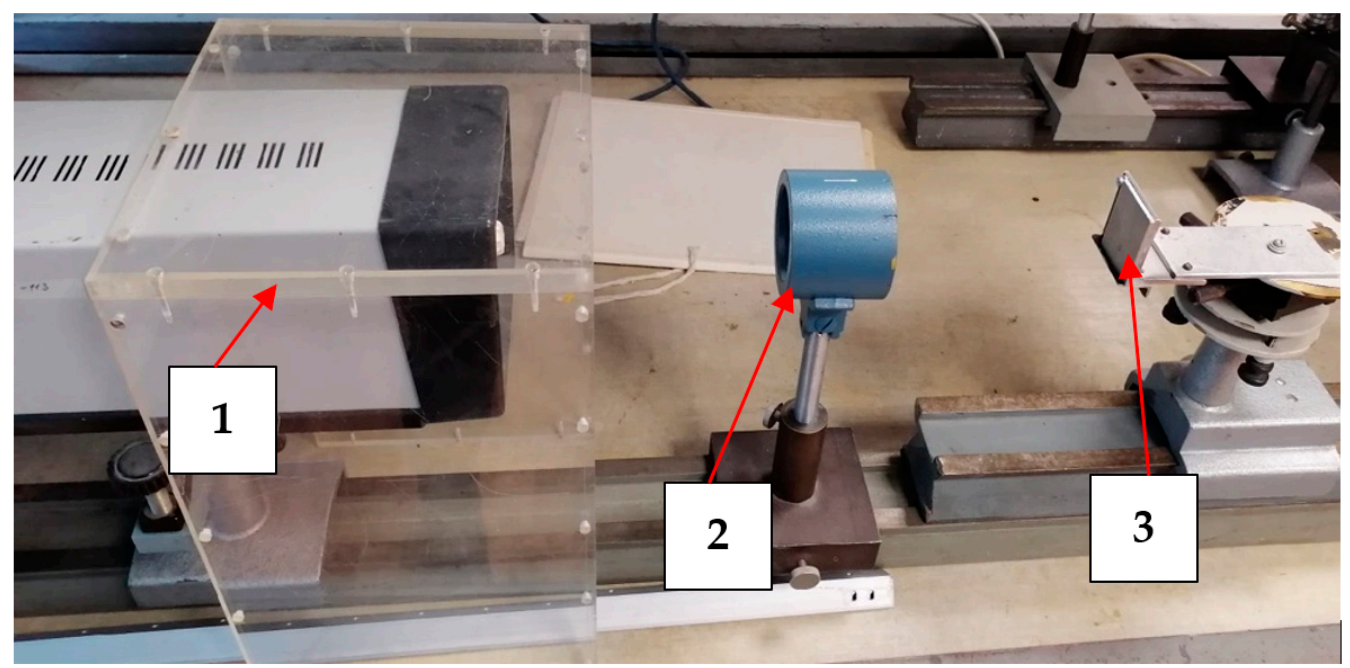

Figure 1. Photo of the optical layout of the Nd:YAG laser experimental setup: (1) Nd:YAG laser with a wavelength of $1064 \mu \mathrm{m}$, (2) focusing lens, and (3) sample surface. The laser focuses a $1064 \mu \mathrm{m}$ beam onto the steel sample.

Laser radiation was focused on the surface of the samples using a special focusing system. The beam was moved across the sample's surface using a high-speed scanning system based on galvanometer mirrors. The maximum output power of the laser in the pulse-periodic treatment mode varied in the range of 3-20 W (which corresponds to a radiation power density of about $1.5 \times 10^{5}-11.2 \times 10^{5} \mathrm{~W} / \mathrm{cm}^{2}$ and an energy density of about $48-152 \mathrm{~J} / \mathrm{cm}^{2}$ ) and in the continuous treatment mode varied in the range of 21-22 W (which corresponds to a radiation power density of about $10.7 \times 10^{5}-11.2 \times 10^{5} \mathrm{~W} / \mathrm{cm}^{2}$ and an energy density of about $0.03-0.1 \mathrm{~J} / \mathrm{cm}^{2}$ ).

The sample processing time was 1-5 s. The metal surface treatment took place at room temperature $\left(23^{\circ} \mathrm{C}\right)$ and $55 \%$ relative humidity.

According to the calculations (as seen in Table 1), the average temperature on the sample surface in the laser treatment zone was: $300.3{ }^{\circ} \mathrm{C}$ (for a laser operating in a repetitively 
pulsed mode) and $308.1^{\circ} \mathrm{C}$ (for a continuously pulsed laser). The speed of the laser beam was $0.05 \mathrm{~m} / \mathrm{s}$ in repetitively pulsed mode and from $0.01 \mathrm{~m} / \mathrm{s}$ to $0.05 \mathrm{~m} / \mathrm{s}$ in CW mood. The laser spot diameter was $50 \mu \mathrm{m}$ for both regimes.

Table 1. Nd:YAG laser parameters used to calculate the temperature.

\begin{tabular}{cccc}
\hline Processing Mode & Power Density, $\mathbf{W} / \mathbf{c m}^{2}$ & Temperature, ${ }^{\circ} \mathbf{C}$ & $\mathbf{V}, \mathbf{~ m} / \mathbf{s}$ \\
\hline Periodically pulsed & $1.5 \times 10^{5}$ & 294.4 & \\
laser radiation & $9.7 \times 10^{5}$ & 301.8 & 0.05 \\
treatment & $10.2 \times 10^{5}$ & 302.2 & \\
& $11.2 \times 10^{5}$ & 303.1 & 0.01 \\
& $10.2 \times 10^{5}$ & 313.6 & 0.01 \\
Continuously pulsed & $10.7 \times 10^{5}$ & 306.7 & 0.025 \\
laser radiation & & 302.7 & 0.01 \\
treatment & $11.2 \times 10^{5}$ & 315.7 & 0.025 \\
& & 307.3 & 0.05 \\
\hline
\end{tabular}

When a body is heated by laser radiation, various processes are activated. When determining the main parameters of this process, it is sufficient to estimate the threshold radiation power density $q_{0}$ (or threshold power $P_{n}$, threshold energy $W_{n}$ ). The threshold radiation power density shows the value at which the specified changes begin to occur in the irradiated material. The theoretical value $\mathrm{q}_{\mathrm{n}}$ is defined as the value of the incident radiation power density, $\mathrm{q}_{0}$, at which the maximum temperature of the processed material reaches the value $T^{*}$ corresponding to the beginning of this process. Threshold characteristics can be determined from an expression that determines the temperature on the surface of the body in the centre of the irradiated area in the form of a circle with a radius $r_{0}$ at the end of the exposure period. For irradiation in the volume absorption mode, these expressions are presented in Equations (1) and (2). In the presented technological process of laser processing, the treated surface is scanned with a laser beam. The results of thermal exposure depend on the scanning speed used.

The temperature was calculated for the repetitively pulsed and continuously pulsed treatment modes according to Equations (1) and (2):

$$
\begin{gathered}
\mathrm{T}=\frac{2 \mathrm{q}_{0} \mathrm{~A} \sqrt{\mathrm{D} \tau}}{\mathrm{k} \sqrt{\pi}}+\mathrm{T}_{\mathrm{i}}, \\
\mathrm{T}=\frac{2}{\sqrt{\pi}} \frac{\mathrm{q}_{0}(1-\mathrm{R})}{\mathrm{K}} \frac{\sqrt{2 \mathrm{Dr}_{0}}}{\mathrm{~V}_{\mathrm{sp}}}+\mathrm{T}_{\mathrm{i}},
\end{gathered}
$$

where: $\mathrm{q}_{0}$-laser radiation power density; $\mathrm{K}$ - thermal conductivity coefficient; $\mathrm{D}$-temperature conductivity; $\mathrm{r}_{0}$ - spot radius; $\mathrm{R}$-metal surface reflectance coefficient; $\mathrm{k}$ - thermal conductivity; $\tau$-duration of exposure; $\mathrm{T}_{\mathrm{i}}$-initial temperature; $\mathrm{V}_{\mathrm{sp}}$ - speed of the laser beam movement relative to the sample surface (scanning speed); A-absorptive capacity of the material.

The values of all the variables used in the calculations are given in Table 2.

Table 2. Carbon steel parameters used to calculate the temperature on the surface.

\begin{tabular}{ccccc}
\hline $\mathbf{R}$ & $\mathbf{D}, \mathbf{~ m}^{\mathbf{2}} \mathbf{s}$ & $\mathbf{K}, \mathbf{W} / \mathbf{m} \cdot \mathbf{K}$ & $\mathbf{r}_{\mathbf{0}}, \mathbf{c m}$ & $\mathbf{T}_{\mathbf{0}}, \mathbf{K}$ \\
\hline 0.63 & $1.172 \times 10^{5}$ & 50 & 0.0025 & 293 \\
\hline
\end{tabular}

Using a JSM-5610 LV scanning electron microscope (Japan) equipped with the EDX JED-2201 chemical analysis system, SEM images of the treated steel surface were obtained and the elemental composition of the samples was determined. 
The change in the surface roughness of the metal was recorded using the contact microprofilometer HOMMEL TESTER T8000 (produced by Hommelwerke GmbH, Germany), and a 3D model of the structure surface was obtained using the stylus profilometer KLA Tencor: P-7 (produced by KLA-Tencor, Milpitas, CA, USA).

In addition, the microstructure of the material surface was examined using an optical light microscope Leica DMI 5000 (produced by Leica Microsystems, Wetzlar, Germany).

\section{Results}

Figure 2 shows an image of the steel surface before treatment with a laser beam, which was recorded using a scanning electron microscope JSM-5610 LV.

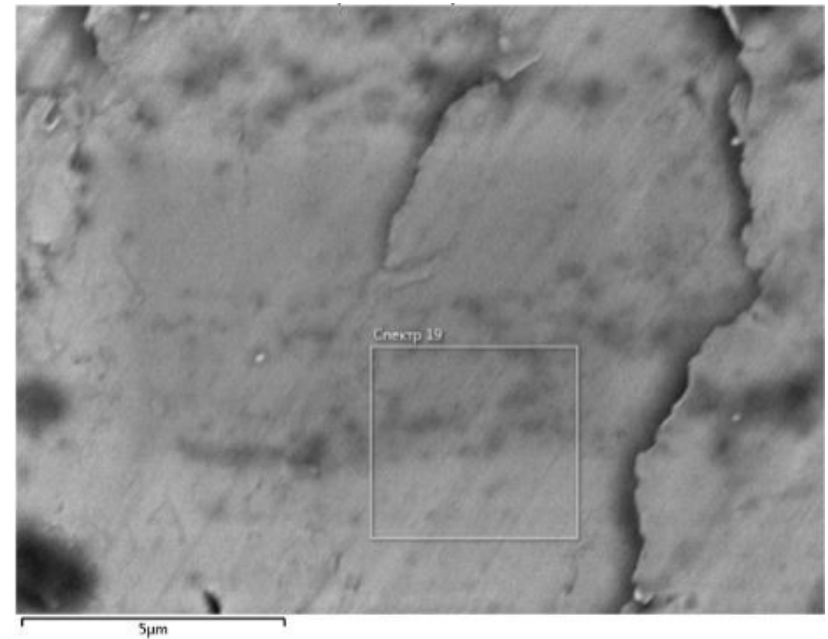

(a)

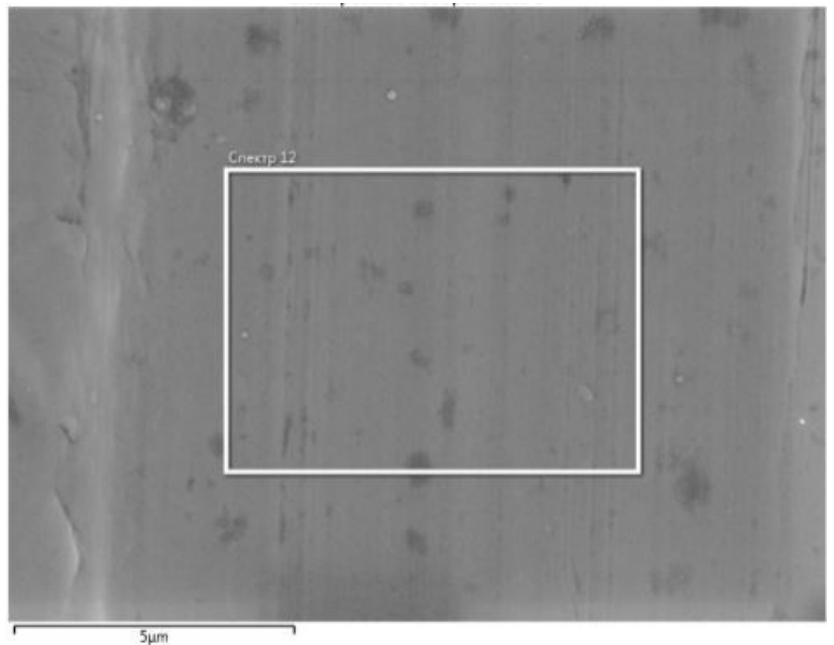

(b)

Figure 2. SEM image of the surface steel (a) before laser treatment and (b) after laser treatment (before connection with chemical reagent).

Under the impact of a laser, anticorrosion layers were formed on the steel surface as a result of the microstructure of a thin surface layer of the steel. Figure $2 b$ shows an image of the steel surface after the laser treatment obtained under a microscope. The effect of laser radiation on the surface of Steel 20 contributed to a slight change in the chemical composition. It was found that the laser treatment resulted in a local redistribution of iron and carbon in the surface layer of the steel, leading to the formation of iron carbide $\left(\mathrm{Fe}_{3} \mathrm{C}\right)$. This effect can be associated with the significant heating of the metal surface.

The changes in the surface roughness of the metal are presented in Table 3. The results obtained allow us to conclude that a significant decrease in the surface roughness of the steel under the influence of a Nd:YAG laser can be obtained using only continuous laser radiation. In Table 3, the samples in which a decrease in surface roughness was observed (from value $R_{a}=0.53 \mu \mathrm{m}$ to $R_{a}=0.38 \mu \mathrm{m}$ ) are highlighted in green; the best result was obtained for No. 7.

In Table 3, the values $R_{a}$ and $R_{z}$ are the arithmetic averages of the absolute values of the deviations of the surface profile within the base length and the sum of the average absolute values of the heights of the five largest profile protrusions and the five largest profile dips within the base length, respectively.

Additionally, the microstructure of the surface of the model samples obtained using an optical light microscope was examined. For metallographic studies, only these samples were selected, the surface roughness of which significantly decreased as a result of laser treatment (in Table 3, they are highlighted in green). For this purpose, the microspecimens used for the qualitative and quantitative analyses of the structure of carbon steel were created. The microspecimens were etched in a 5\% solution of nitric acid with the addition of water. Figure 3 shows a general view of the etched surface, and it can be concluded that the steel under examination had a ferrite-pearlite structure. 
Table 3. The surface roughness of the model samples before and after laser treatment by Nd:YAG laser.

\begin{tabular}{|c|c|c|c|}
\hline \multirow{2}{*}{ № } & \multirow{2}{*}{ Processing Mood } & \multicolumn{2}{|c|}{ Treated Material } \\
\hline & & $\mathbf{R}_{\mathbf{a}}, \boldsymbol{\mu m}$ & $\mathbf{R}_{\mathrm{z}}, \mu \mathrm{m}$ \\
\hline 1 & Treatment with pulsed-periodic laser radiation & 1.22 & 7.20 \\
\hline 2 & Continuous laser radiation treatment & 0.47 & 2.86 \\
\hline 3 & Continuous laser radiation treatment & 0.44 & 2.80 \\
\hline 4 & Treatment with pulsed-periodic laser radiation & 1.40 & 9.05 \\
\hline 5 & Continuous laser radiation treatment & 0.61 & 4.10 \\
\hline 6 & Continuous laser radiation treatment & 0.60 & 3.71 \\
\hline 7 & Continuous laser radiation treatment & 0.49 & 2.76 \\
\hline 8 & Treatment with pulsed-periodic laser radiation & 1.12 & 7.65 \\
\hline 9 & Continuous laser radiation treatment & 0.38 & 3.17 \\
\hline 10 & Continuous laser radiation treatment & 0.51 & 3.62 \\
\hline 11 & Treatment with pulsed-periodic laser radiation & 0.70 & 5.85 \\
\hline \multirow[t]{2}{*}{12} & Continuous laser radiation treatment & 0.40 & 2.72 \\
\hline & Raw material & 0.53 & 3.66 \\
\hline
\end{tabular}

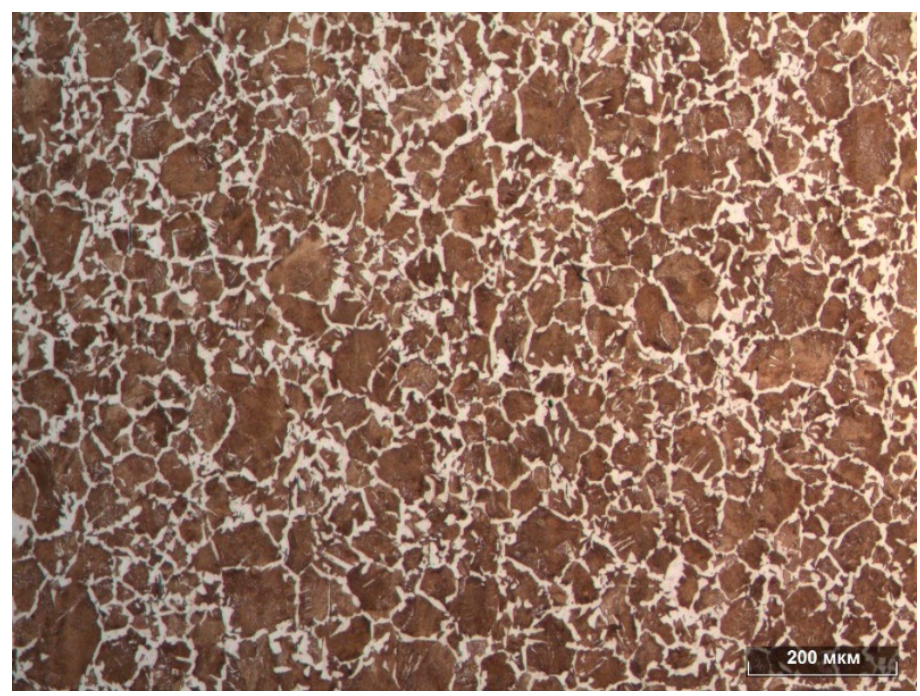

Figure 3. The surface of the etched micro-sections under a microscope at $100 \times$ magnification.

Among the analysed samples (Table 3), the best results were shown by samples No. 7 and No. 12.

Figures 4 and 5 show the microstructure of the steel surface treated with an Nd:YAG laser. At the edge of the macrophotography in the cross-section of the micro specimen in Figures 4 and 5, we can clearly see a white stripe, which is a corrosion-resistant layer of steel formed as a result of laser treatment. The best results were obtained with strong carbon diffusion. 


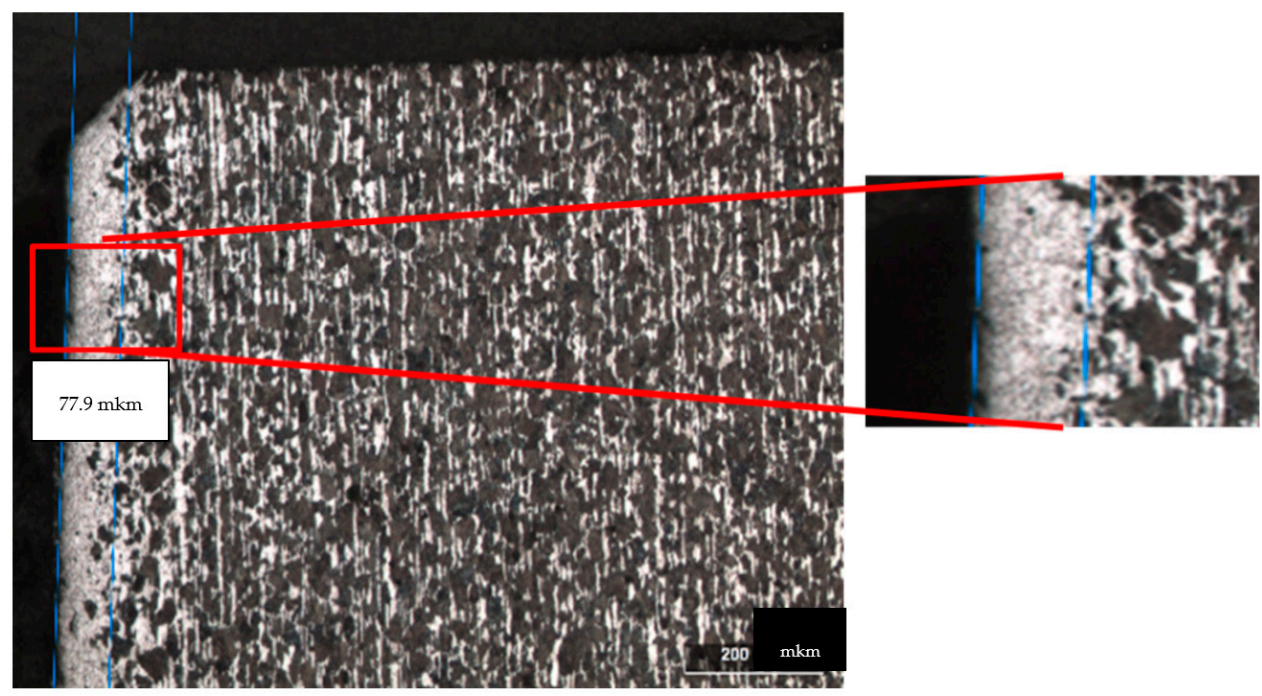

Figure 4. An image of the transverse structure of the microscope of the Nd:YAG laser-treated steel surface obtained with an optical microscope. Sample No. 7.

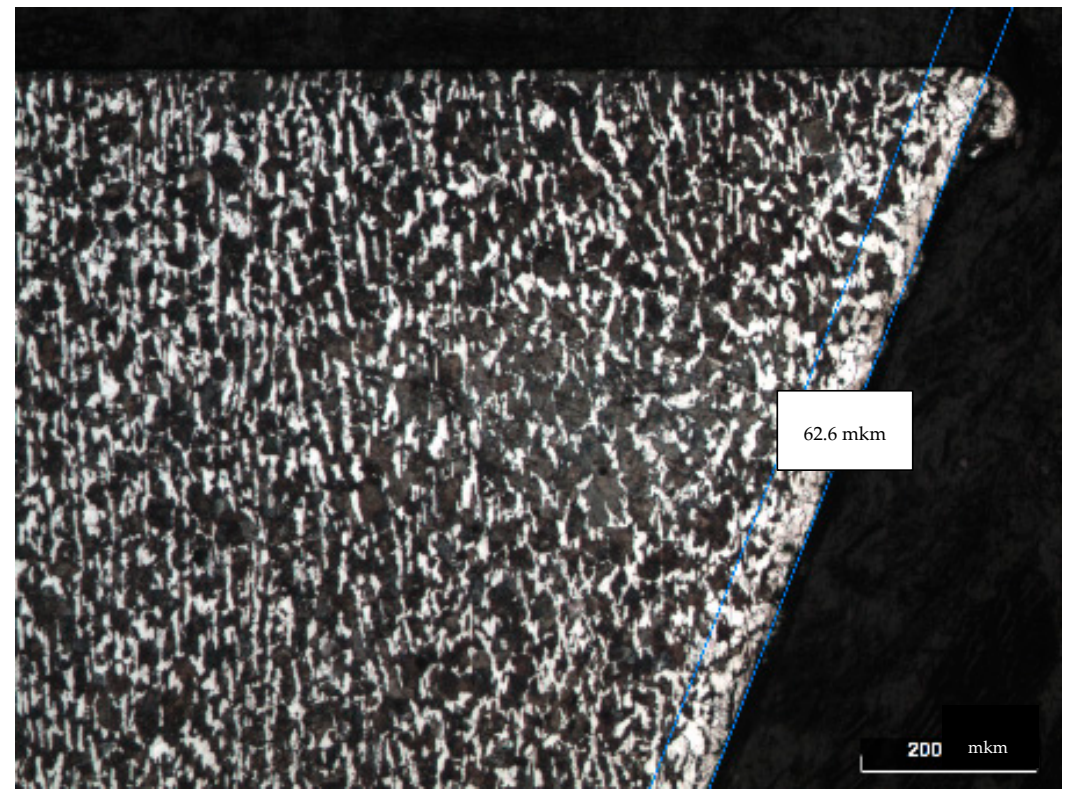

Figure 5. An image of the transverse structure of the microscope of the Nd:YAG laser-treated steel surface obtained with an optical microscope. Sample No. 12.

Sample No. 7 distinguishes itself by a pronounced dense protective layer with an $\mathrm{h}=77.9 \mu \mathrm{m}$ thickness. A decrease and compaction of the grains is evident, which is a positive result and indicates the high quality of the layer and its high corrosion resistance. The disadvantages of this treatment mode (power density $\mathrm{q}=10.2 \times 10^{5} \mathrm{~W} / \mathrm{cm}^{2}$ ) include the uneven temperature distribution across the sample; as a result, in some places, a decrease in thickness to $h=31.5 \mu \mathrm{m}$ and a porous structure are observed.

Sample No. 12 is distinguished by a uniformly distributed protective layer with an $\mathrm{h}=62.5 \mu \mathrm{m}$ thickness. A decrease and compaction of the grains can be seen, which is a positive result, as in sample No. 7. The disadvantages of this treatment mode (power density $\mathrm{q}=10.7 \times 10^{5} \mathrm{~W} / \mathrm{cm}^{2}$ ) include the insufficiently dense anticorrosion coating structure, similar to that of sample No. 7 .

Samples with the best treatment results were subjected to corrosion testing. The following solutions were chosen as the electrolyte for the electrochemical method used for determining the corrosion rate: $3 \% \mathrm{NaCl}$ and $3 \% \mathrm{Na}_{2} \mathrm{SO}_{4}$. These solutions were chosen 
due to the fact that they simulate the occurrence of real aggressive conditions in the natural environment during the storage and operation of historical monuments. The samples prepared for testing were coated with a layer of hot adhesive compound made of rosin with wax, leaving the untreated area of about $0.54 \mathrm{~cm}^{2}$, and afterwards were placed into the abovementioned saline solutions. Figure 6 shows the results obtained from measuring the electric potential over time on a steel surface not treated with a laser, which were adopted as standard. The measurements were carried out using the IPC-Pro M potentiostat. As a result of testing in both solutions, an active release of iron $(\mathrm{Fe})$ into the environment was observed, leading to active corrosion processes.

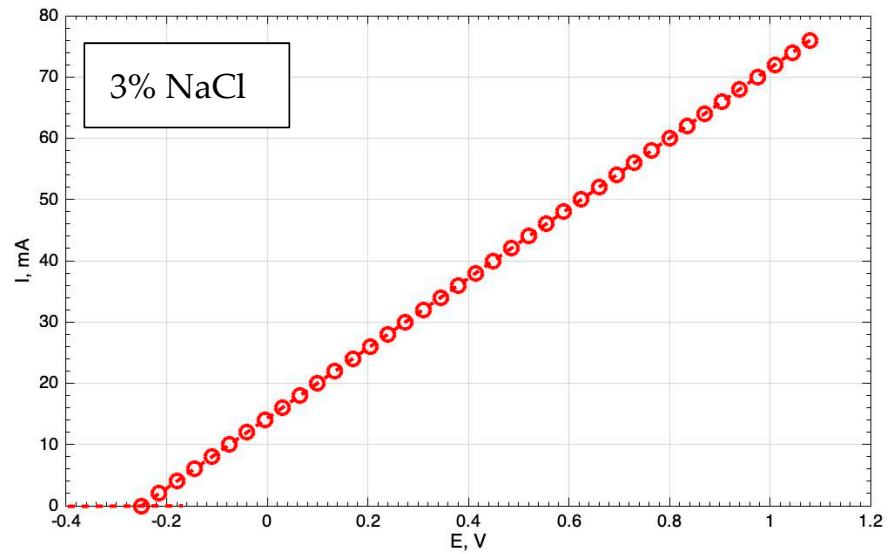

(a)

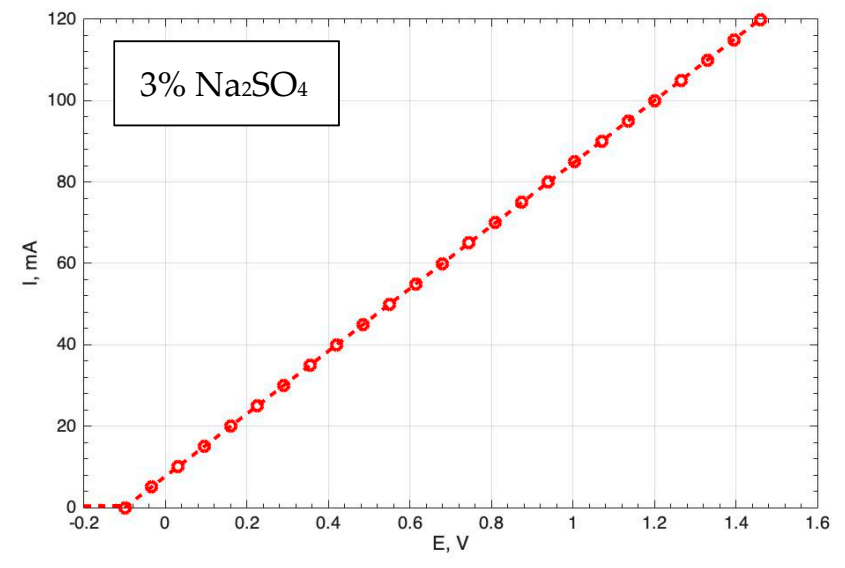

(b)

Figure 6. Potentiostatic polarisation curves on the untreated laser surface of steel in (a) $3 \% \mathrm{NaCl}$ and (b) $3 \% \mathrm{Na}_{2} \mathrm{SO}_{4}$.

It is impossible to create potentiostatic polarisation curves for the samples with protective coatings. However, as a result of these corrosion studies, it was found that the coatings formed on the surface of the steel samples using an Nd:YAG laser do not transmit electric current, and this confirms the fact that the obtained anticorrosion coatings have high protective properties. This is an important advantage of the anticorrosion coatings obtained by laser treatment.

\section{Discussion}

The conducted studies have shown the potential of enhancing the corrosion resistance of steel through treatment with continuous and repetitively pulsed Nd:YAG laser radiation generated at a wavelength of $1.064 \mu \mathrm{m}$. As a result of these experiments, the optimal operating modes of the laser treatment were determined, including the level of radiation power density at which the formation of a protective anticorrosion layer takes place. This is around $10.2 \times 10^{5} \mathrm{~W} / \mathrm{cm}^{2}$ and $10.7 \times 10^{5} \mathrm{~W} / \mathrm{cm}^{2}$ for the continuous and repetitive laser generating modes, respectively. Under such conditions, a protective anticorrosion coating with a thickness of about $62-77 \mu \mathrm{m}$ was obtained on the steel surface.

It should be noted that in the experiments an interesting effect was observed. As a result of the laser processing of steel, various colour shades (including blue and light-blue colours) sometimes appeared on its surface; see Figure 7. 


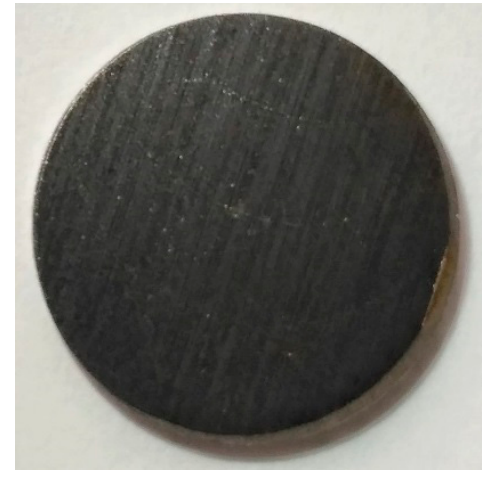

(a)

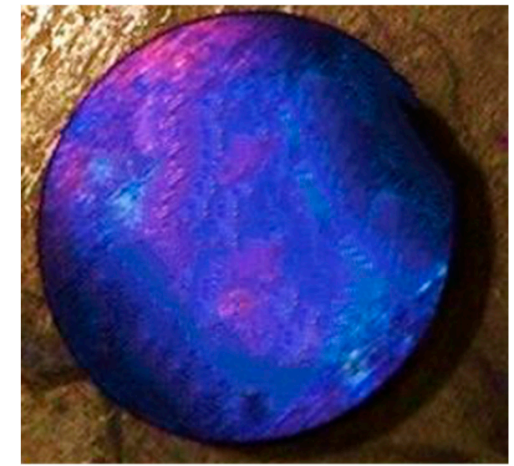

(b)

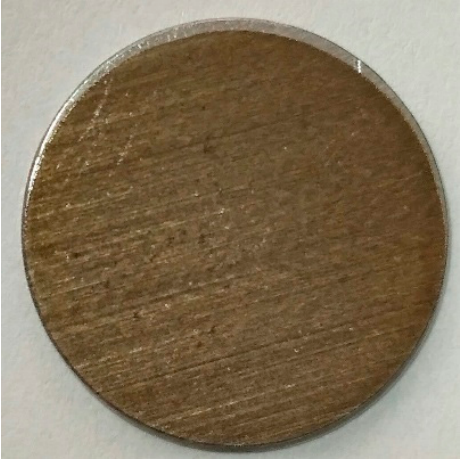

(c)

Figure 7. Colour shades on the steel surface after laser treatment: (a) black; (b) blue; (c) gold.

This opens up possibilities for the use of Nd:YAG lasers to restore the artistic finishing (colour appearance) of decorative art objects made of steel. The possibility of carrying out this restoration task with the help of laser treatment has been discussed previously in one of our articles [12].

Regarding the results obtained in this work, the main conclusion that can be drawn on the basis of the experimental studies conducted lies in the fact that the laser treatment of iron-based metallic materials using continuous-wave and repetitively pulsed Nd:YAG lasers generated at a wavelength of $1.064 \mu \mathrm{m}$ allows the problem of the passivation of the surface of such materials to be solved. Therefore, the approach proposed in this article may be considered as a promising way to passivate the surface of $\mathrm{CH}$ objects created from iron, steel, and cast iron. However, it should be noted that this conclusion is preliminary and needs experimental validation. Since, in these experiments, we used only model samples in order to make our conclusions more general, it is necessary to conduct experiments on the laser passivation of authentic historical artifacts, the surfaces of which are inhomogeneous as a result of weathering and the removal of corrosion layers in the course of conservation works. The authors do plan to carry out such studies in the near future in collaboration with professional restorers.

Meanwhile, it is without doubt that laser treatment allows one to defend newly created metallic artworks against corrosion.

\section{Conclusions}

The experimental results obtained regarding the laser treatment of carbon steel model samples by the radiation of repetitively pulsed and continuous-wave $1.064 \mu \mathrm{m}$ Nd:YAG lasers are described in the present article. We can conclude that the laser treatment allows the formation of dense protection films on the steel surface, which enhance the anticorrosion properties of the metal. The application of Nd:YAG lasers is a promising means for the surface passivation of artworks created from steel and cast iron. One possible explanation for this may be that laser treatment results in the local redistribution of iron and carbon in the surface layer of the steel, which leads to the formation of iron carbide $\left(\mathrm{Fe}_{3} \mathrm{C}\right)$. This effect can be associated with the significant heating of the metal surface. It is known from the scientific literature [13] that, under a temperature change in steel in the range of $600-100{ }^{\circ} \mathrm{C}$ (which fits our case), the elements iron (Fe), cobalt (Co) and nickel (Ni) can form carbide iron $\left(\mathrm{Fe}_{3} \mathrm{C}\right)$ due to chemical reactions with carbon. The specified microstructuring of the steel surface can increase its corrosion resistance. The iron pillar of Delhi is an example of steel with a high percentage of Fe being saved from corrosion. 


\begin{abstract}
Author Contributions: Conceptualisation, I.R. and V.P.; methodology, I.R., V.P. and O.V.; validation, I.R., V.P. and O.V.; formal analysis, O.Z.; investigation, O.Z. and A.Z.; resources, O.V.; data curation, I.R.; writing—original draft preparation, I.R.; writing—review and editing, V.P.; visualisation, I.R.; supervision, V.P.; project administration, I.R. All authors have read and agreed to the published version of the manuscript.
\end{abstract}

Funding: This research received no external funding.

Institutional Review Board Statement: Not applicable.

Informed Consent Statement: Not applicable.

Data Availability Statement: The data supporting the findings of this study are available from the corresponding author upon reasonable request.

Acknowledgments: The authors would like to thank V.G. Bondarenko and S.R. Rustamov (both are with the R\&D Institute "Polyus", Moscow) for their assistance in experiments using Nd:YAG lasers.

Conflicts of Interest: The authors declare no financial or commercial conflict of interest.

\title{
References
}

1. Nikitin, M.K.; Melnikova, E.P. Chemistry in Restoration; Khimiya: Leningrad, Russia, 1990.

2. Emelyanenko, A.M.; Shagieva, A.G.; Domantovsky, A.G.; Boinovich, L.B. Nanosecond laser micro- and nanotexturing for the design of a superhydrophobic coating robust against long-term contact with water, cavitation, and abrasion. Appl. Surf. Sci. 2015, 332, 513. [CrossRef]

3. Vorobyev, A.Y.; Ghunlei, G. Multifunctional surfaces produced by femtosecond laser pulses. J. Appl. Phys. 2015, 117, 3. [CrossRef]

4. Osticioli, I.; Siano, S. Dependence of Nd: YAG laser derusting and passivation of iron artifacts on pulse duration. In Proceedings of the SPIE 9065, Fundamentals of Laser-Assisted Micro- and Nanotechnologies, St. Petersburg, Russia, 24-28 June 2013 ; p. 906513.

5. Siano, S.; Agresti, J.; Cacciari, I.; Ciofini, D.; Mascalchi, M.; Osticioli, I.; Mencaglia, A.A. Laser cleaning in conservation of stone, metal, and painted artifacts: State of the art and new insights on the use of the Nd: YAG lasers. Appl. Phys. A 2012, $106,419$. [CrossRef]

6. Tareen, J.; Krishnamurthy, K.V. Hydrothermal stability of hematite and magnetite. Bull. Mater. Sci. 1981, 3, 9. [CrossRef]

7. Vasiliev, O.V.; Veiko, V.P.; Gornyi, S.G.; Ruzankina, Y.S. Laser apparatus for microstructuring a metal surface, using a fiber laser. J. Opt. Technol. 2015, 82, 831. [CrossRef]

8. Ruzankina, J.S.; Parfenov, V.A.; Vasiliev, O.S. Anti-corrosion prevention of carbon steel by means of laser treatment. Laser Phys. 2019, 29, 015203. [CrossRef]

9. Iakovlev, A.; Ruzankina, J.; Kasheev, S.; Vasilyev, O.; Parfenov, V.; Grishkanich, A. Laser anti-corrosion treatment of metal surfaces. In Proceedings of the SPIE 10097, High-Power Laser Materials Processing: Applications, Diagnostics, and Systems VI, San Francisco, CA, USA, 28 January-2 February 2017; p. 100970 S.

10. Ruzankina, J.S.; Vasiliev, O.S. Study on possibility for the improvement of corrosion resistance of metals using laser-formed oxide surface structure. J. Phys. Conf. Ser. 2016, 735, 012050. [CrossRef]

11. Ruzankina, J.S.; Vasiliev, O.S.; Parfenov, V.A. Anti-corrosion treatment of metal surfaces based on photonics methods. J. Phys. Conf. Ser. 2017, 917, 062039. [CrossRef]

12. Gerashenko, M.D.; Parfenov, V.A. Formation of non-ferrous oxide films on the surface of metals under the influence of laser radiation. Bull. St. Petersburg State Electrotech. Univ. LETI 2011, 3, 68.

13. Glinka, N.K. Nauka; Khimiya: Moscow, Russia, 2017; p. 752. 